УДК 550.832

\title{
ПРИМЕНЕНИЕ СЕЙСМОФАЦИАЛЬНОГО АНАЛИЗА ДЛЯ ОЦЕНКИ ПЕРСПЕКТИВ СЛОЖНОПОСТРОЕННЫХ КАРБОНАТНЫХ КОЛЛЕКТОРОВ НА ПРИМЕРЕ НЕФТЯНОГО МЕСТОРОЖДЕНИЯ (ПО ДАННЫМ ГЕОФИЗИЧЕСКИХ ИССЛЕДОВАНИЙ СКВАЖИН)
}

\author{
Чучалина Кристина Юрьевна' ${ }^{1}$ \\ K.Yu.Chuchalina@gmail.com
}

\author{
Коровин Михаил Олегович1, \\ korovinmo@hw.tpu.ru \\ 1 Национальный исследовательский Томский политехнический университет,
Россия, 634050, г. Томск, пр. Ленина, 30.
}

\begin{abstract}
Актуальность исследования определена необходимостью минимизации неопределенностей геологической интерпретации благодаря применению различных классификационных алгоритмов в процессе обработки всего комплекса геологогеофизических данных.

Цель: прогноз и статистическое обоснование распределения фаций на основе геофизической информации на примере одного из месторождений Томской области.

Объектом исследования являются палеозойские отложения юго-восточной части Западно-Сибирской плиты - коллекторы сложнопостроенных карбонатных толщ, где встречаются терригенные образования и карбонатные разности - известняк и доломит. Исходя из условий построения сейсмофрациальной карты, было выбрано окно исследования, которое охватывает объем горной породы равньй $40 \mathrm{M}$.

Методы исследования основаны на применении классификационных алгоритмов к сейсмическому сигналу, которые разделяют исследуемый объект на однородные по ряду признаков области. В классификационный алгоритм по сейсмической трассе очень часто включают геофизические исследования скважин и лабораторные исследования керна, что подразумевает комплексирование инсрормации. Комплексная интерпретация сейсмических и скважинных данных позволяет прогнозировать на качественном уровне литофациальную изменчивость на локальных участках, что способствует более рациональному размещению эксплуатационных скважин.

В результате исследования выделены и ранжированы литотипы пород продуктивной толщи на основе сравнения сейсмического параметра - акустический импеданс, по данным скважинной и сейсмической инфрормации. Сопоставление данных осуществлено с помощью восстановленных измерений плотностного каротажа. Предложенная схема комплексирования информации для перспектив нефтегазоносности палеозойских отложений на примере нефртяного месторождения Западной Сибири позволит выделить перспективные зоны для планирования бурения новых скважин.
\end{abstract}

\section{Ключевые слова:}

Сейсмофрациальный анализ, сейсмофрациальная карта, фация, геофизические исследования скважин, акустический импеданс, палеозойские отложения.

\section{Введение}

На изучаемом месторождении отмечается палеозойский стратиграфический диапазон нефтегазоносности - от среднего до позднего девона. В течение среднего и верхнего девона территория подвергалась активным тектоническим воздействиям, в результате чего был сформирован органогенный биогерм. С северо-востока данный биогерм был ограничен открытым глубоководным бассейном, а с юго-запада - изолированным мелководным морем [1-3]. Исходя из сложных геологических условий необходимо комплексировать геолого-геофизическую информацию.

Для анализа распределения фаций были получены сейсмофациальная карта и комплекс заранее выбранных сейсмических атрибутов [4, 5]. При построении сейсмофациальной карты были использованы сейсмические атрибуты, которые способствуют выделению зон с отличающимися характеристиками волнового поля, выявлению геологических объектов и оконтуриванию аномальных зон. Комплекс сейсмических атрибутов включал следующий набор [6-8]: мгновенная частота, мгновенная фаза, мгновенное качество, относительный акустический импеданс, первая производная, затухание.
Сейсмофациальная карта, используемая для статистического обоснования сложнопостроенных карбонатных толщ изучаемого месторождения, представлена на рис. 1.

\section{Геофизические методы изучения}

сложнопостроенных карбонатных коллекторов

Для изучения карбонатных коллекторов наиболее распространёнными являются следующие геофизические методы: гамма каротаж, нейтронный гамма каротаж, методы сопротивления, а также методы акустического и плотностного каротажей [9], последние из которых позволяют определить акустические свойства пород, что предполагает комплексирование геофизических данных с сейсмической информацией. На примере изучаемого нефтяного месторождения был проведен анализ ГИС (геофизические исследования скважин) во всех скважинах, кроме 4R, из-за отсутствия измерений (табл. 1).

На основе данных, представленных в табл. 1, стоит отметить, что в более $50 \%$ фонда скважин невозможно напрямую определить акустические свойства пласта по причине отсутствия измерений акустического каротажа. Более того, отсутствуют исследования плотности 
горных пород, что является важным параметром для изучения распространения литотипов на месторождении. Из этого следует, что отсутствие полного ком- плекса геофизических исследований предполагает комплексирование имеющейся геофизической информации и данных лабораторных исследований керна.

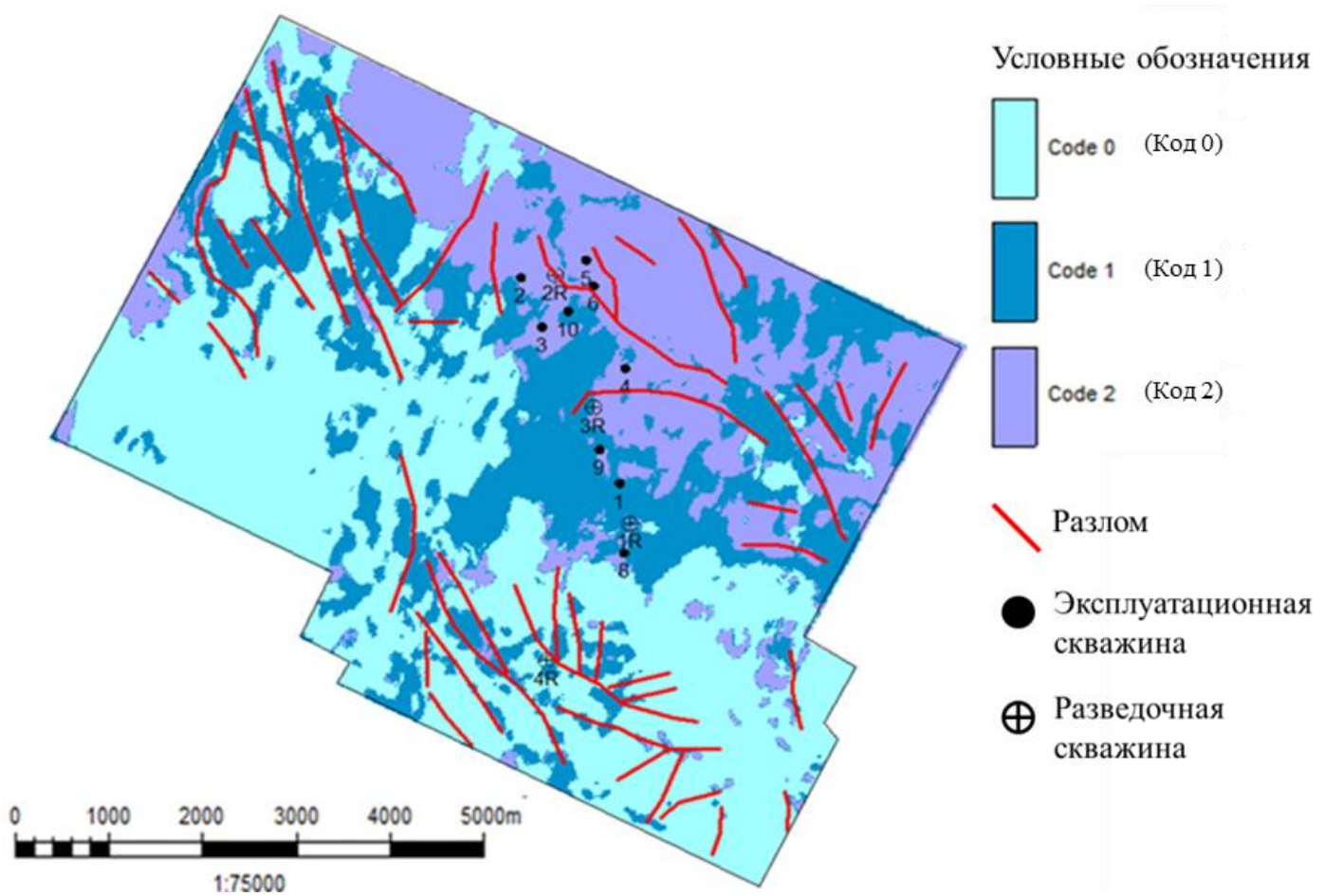

Рис. 1. Сейсмофачиальная карта по кровле фундамента Ф2

Fig. 1. Seismic facies map on the top of the foundation F2

Таблица 1. Сводные данные комплекса ГИС

Table 1. Summary data of the well logs

\begin{tabular}{|c|c|c|c|c|c|c|}
\hline $\begin{array}{c}\text { Каротаж } \\
\text { Well logging }\end{array}$ & ГК & ПС & AK & AKs & ИК & HKT \\
\hline $\begin{array}{l}\text { Скважина № } \\
\text { Well no. }\end{array}$ & GR & SP & DT & DTS & IK & Neut \\
\hline 5 & + & + & - & - & - & + \\
\hline 6 & + & + & - & - & + & + \\
\hline 2 & + & + & + & + & + & + \\
\hline $2 \mathrm{R}$ & + & + & + & - & + & + \\
\hline 10 & + & + & + & + & + & + \\
\hline 1 & + & + & + & - & + & + \\
\hline $1 \mathrm{R}$ & + & + & + & - & + & + \\
\hline 4 & + & + & - & - & - & + \\
\hline $4 \mathrm{R}$ & - & - & - & - & - & - \\
\hline 3 & + & + & - & - & - & + \\
\hline $3 R$ & + & + & + & - & + & + \\
\hline 9 & + & + & - & - & - & + \\
\hline 8 & + & + & - & - & - & + \\
\hline
\end{tabular}

ГK - гамма каротаж (GR - Gamma Ray), ПC - каротаж сопротивления (SP - Resistivity Log), AK - акустический каротаж продольной волны (DT - Acoustic Log), $A K_{S}-$ акустический каротаж поперечной волны (DTS Acoustic Log of Secondary wave), ИК - индукиионный каротаж (IK - Induction Log), НКT - нейтронный каротаж (Neut - Neutron Log).

Расчленение разреза для выделения литотипов в каждой скважине было осуществлено с помощью комплекса ГИС: низкая радиоактивность, высокие значения сопротивления и нейтронного каротажа для карбонатных отложений; низкие значения сопротив- ления, средние и низкие значения нейтронного каротажа для глинисто-кремнистых пород; а также были выделены эффузивы исходя из высоких значений индукционного каротажа и радиоактивности [10, 11]. Сводная панель геолого-геофизических материалов для скважин № 1-1R-3R представлена на рис. 2. Необходимо отметить, что для выделения литотипов было принято ограничение в объеме окна исследования, которое охватывает объем горных пород от кровли палеозойских отложений мощностью $40 \mathrm{M}$. На основе проведенной корреляции пород в объеме окна исследования 40 м в каждой скважине было выделено процентное содержание фаций. Результаты статистической оценки представлены в табл. 2.

Согласно статистическому анализу распределения фаций (табл. 2), можно выделить три группы скважин по преобладающему литотипу, что позволяет сопоставить каждую группу скважин с кластерами фаций, расположенных на сейсмофациальной карте:

1) Глинисто-кремнистые породы - скважина № 4R.

2) Доломит - скважины № 2R, 1R и 3R.

3) Известняк - скважины № 5, 6, 2, 10, 1, 4, 3, 8, 9 .

При сопоставлении полученных результатов с сейсмофациальной картой (рис. 1) было принято решение каждому коду на карте присвоить определенный литотип горной породы:

1) Код 0 - глинисто-кремнистые породы.

2) Код $1-$ известняк.

3) Код 2 - доломит. 
Таблица 2. Сводная таблица статистического анализа фаций на основе данных ГИС (геофизические исследования скважин)

Table 2. $\quad$ Summary table of statistical analysis of facies based on well logs data

\begin{tabular}{|c|c|c|c|c|c|c|}
\hline $\begin{array}{c}\text { Литотип, \% } \\
\text { Lithotype, \% } \\
\text { Скважина № } \\
\text { Well no. }\end{array}$ & $\begin{array}{c}\text { Глинисто-кремнистые } \\
\text { Argillaceous-siliceous }\end{array}$ & $\begin{array}{l}\text { Алевролиты } \\
\text { Siltstone }\end{array}$ & $\begin{array}{l}\text { Доломит } \\
\text { Dolomite }\end{array}$ & $\begin{array}{l}\text { Известняк } \\
\text { Limestone }\end{array}$ & $\begin{array}{l}\text { Эффузивы } \\
\text { Effusive }\end{array}$ & $\begin{array}{c}\text { Преобладающий литотип } \\
\text { Prevailing type }\end{array}$ \\
\hline 5 & - & - & 30,5 & 69,50 & - & $\begin{array}{l}\text { Известняк } \\
\text { Limestone }\end{array}$ \\
\hline 6 & 5,00 & 2,50 & 17,50 & 70,00 & 5,00 & $\begin{array}{l}\text { Известняк } \\
\text { Limestone }\end{array}$ \\
\hline 2 & 4,71 & 3,62 & 17,39 & 71,02 & 3,26 & $\begin{array}{l}\text { Известняк } \\
\text { Limestone }\end{array}$ \\
\hline $2 \mathrm{R}$ & 8,49 & - & 69,00 & - & 22,5 & $\begin{array}{l}\text { Доломит } \\
\text { Dolomite } \\
\end{array}$ \\
\hline 10 & 18,21 & - & 10,59 & 62,28 & 8,89 & $\begin{array}{l}\text { Известняк } \\
\text { Limestone }\end{array}$ \\
\hline 1 & 10 & - & 9,50 & 76,00 & 4,49 & $\begin{array}{l}\text { Известняк } \\
\text { Limestone }\end{array}$ \\
\hline $1 \mathrm{R}$ & 1,99 & - & 60,00 & 37,99 & - & $\begin{array}{l}\text { Доломит } \\
\text { Dolomite }\end{array}$ \\
\hline 4 & - & - & 17,27 & 82,73 & - & $\begin{array}{l}\text { Известняк } \\
\text { Limestone }\end{array}$ \\
\hline $4 R$ & 100 & - & - & - & - & $\begin{array}{c}\text { Глинисто-кремнистые } \\
\text { Argillaceous-Siliceous }\end{array}$ \\
\hline 3 & - & - & 40,43 & 59,57 & - & $\begin{array}{l}\text { Известняк } \\
\text { Limestone }\end{array}$ \\
\hline $3 R$ & - & - & 69,50 & 24,00 & 6,49 & $\begin{array}{l}\text { Доломит } \\
\text { Dolomite }\end{array}$ \\
\hline 9 & - & - & 45,14 & 54,86 & - & $\begin{array}{l}\text { Известняк } \\
\text { Limestone }\end{array}$ \\
\hline 8 & - & - & 67,15 & 32,85 & - & $\begin{array}{l}\text { Доломит } \\
\text { Dolomite }\end{array}$ \\
\hline
\end{tabular}

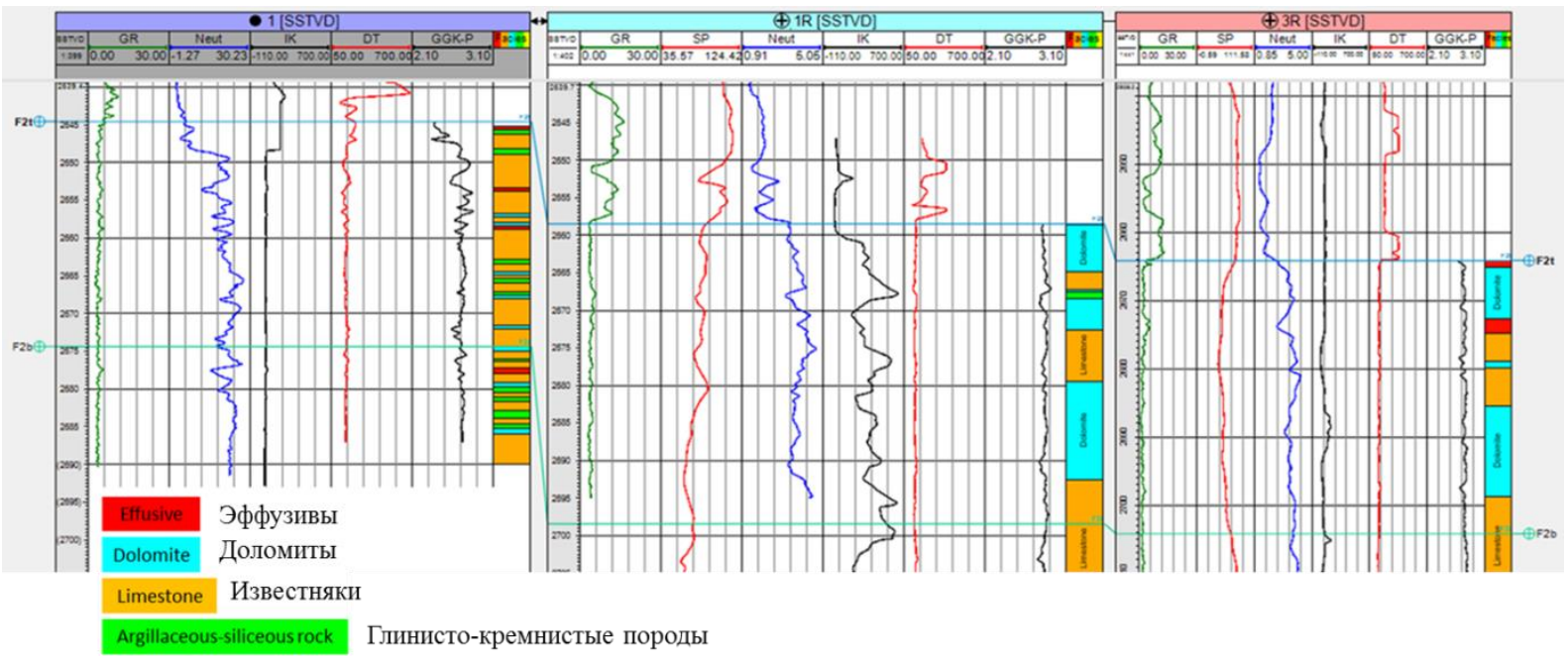

GR (Gamma Ray) - ГК (гамма каротаж), SP (Resistivity Log) - ПС (каротаж сопротивления), Neut (Neutron Log) HКT (нейтронный каротаж), IK (Induction Log) - ИК (индукционный каротаж), DT (Acoustic Log) - AK (акустический каротаж продольной волны), GGK-P (gaтma-gamma density Log) - ГГК-П (плотностной гаммагамма каротаж).

Puc. 2. Корреляционная панель по скважинам № $1-1 R-3 R$

Fig. 2. Correlation panel for wells no. 1-1R-3R

В результате сопоставления данных получается, что возникает расхождение между скважинной и сейсмической информацией в районе скважин № $5,6,2 \mathrm{R}$, 2,10 . Эти расхождения связаны с наличием геологических неопределенностей, некорректной интерпретацией ГИС, которая обусловлена недостаточной разрешающей способностью. Для уменьшения неопре- деленности геологического строения было принято решение проанализировать упругие свойства горных пород, используя зависимости на основе материалов ГИС, а также провести анализ кернового материала.

Для распределения фаций были проведены расчёты акустического импеданса, которые позволяют выделить фациальную изменчивость пространства гор- 
ной породы [12]. Акустический импеданс рассчитывался на основе данных ГИС. С учетом всех вышеизложенных условий, где исследования акустического каротажа представлены в ограниченном объеме, а исследования плотности горных пород на изучаемой территории не проводились, возникают трудности для анализа фациального строения. Из-за отсутствия полного комплекса ГИС также не предоставляется возможным рассчитать акустический импеданс, так как расчет акустического импеданса производится по следующей формуле [13]:

$$
A I=V_{p}^{*} p
$$

где $A I$ - акустический импеданс, м/ $\mathrm{c}^{*} / \mathrm{cm}^{3} ; V_{p}$ - скорость продольной волны, м/с; $p$ - плотность горной

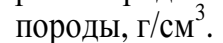

Были рассмотрены четыре варианта получения зависимостей для расчета плотности горной породы в исследуемом интервале [14-16]:

Вариант 1. Зависимость между АК и ГГК-П каротажами, где измерения проводились в горизонтальном стволе эксплуатационной скважины на глубине 2913 м (рис. 3). Рассматривая данный вариант, необходимо учитывать тот факт, что измерения проводились в горизонтальном стволе, а применить полученную зависимость необходимо на вертикальную или наклонно-направленную скважины. Исходя из этого, возникает вопрос о корректности расчетных значений при использовании этой зависимости. Поэтому было предложено рассмотреть другие варианты построения зависимостей.

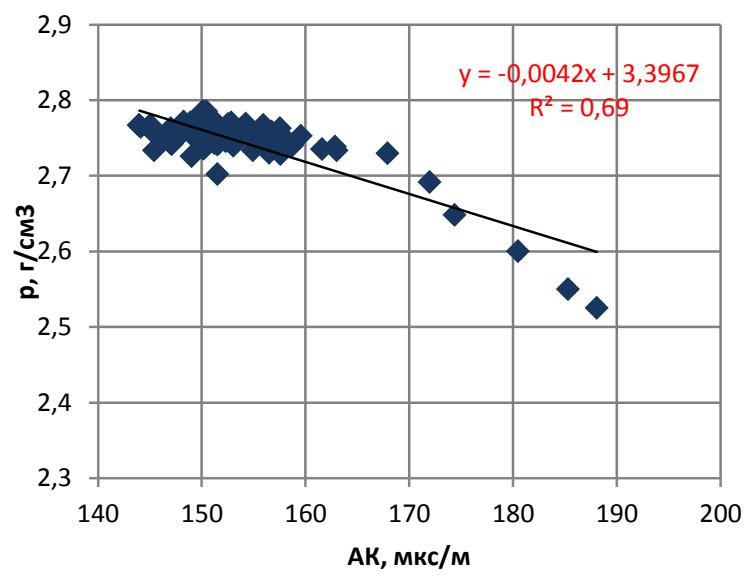

Pис. 3. Зависимость акустического и плотностного каротажа

Fig. 3. Dependence of acoustic and density logging

Полученная зависимость на основе измерений в горизонтальном стволе эксплуатационной скважины № 2 представляет хорошую корреляционную связь, но физический смысл проведения работ в горизонтальном стволе не позволяет использовать данное уравнение для расчетов в наклонно-направленных скважинах.

Вариант 2. Зависимость гамма каротажа и значений плотности горных пород из лабораторных исследований эксплуатационной скважины № 2 (рис. 4).

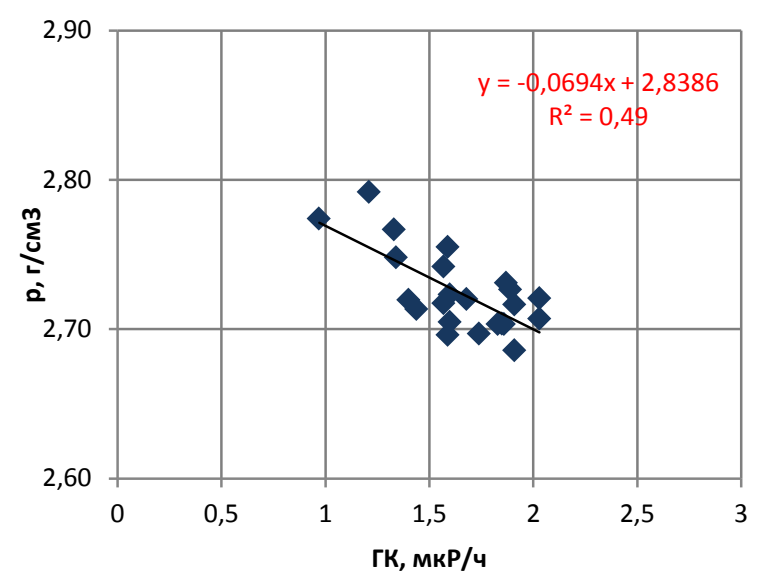

Pис. 4. Зависимость гамма каротажа и плотности горной породы по керновым даннылм

Fig. 4. Dependence of gamma logging and rock density according to core data

Для проверки корректности расчетных значений было осуществлено сопоставление полученных значений плотности по ГИС со значениями плотности горных пород на основе лабораторных исследований керна, результат представлен на рис. 5. Исходя из сопоставления видно, что использование данной корреляционной зависимости для получения упругих свойств пород является невозможным, так как наблюдается расхождение данных.

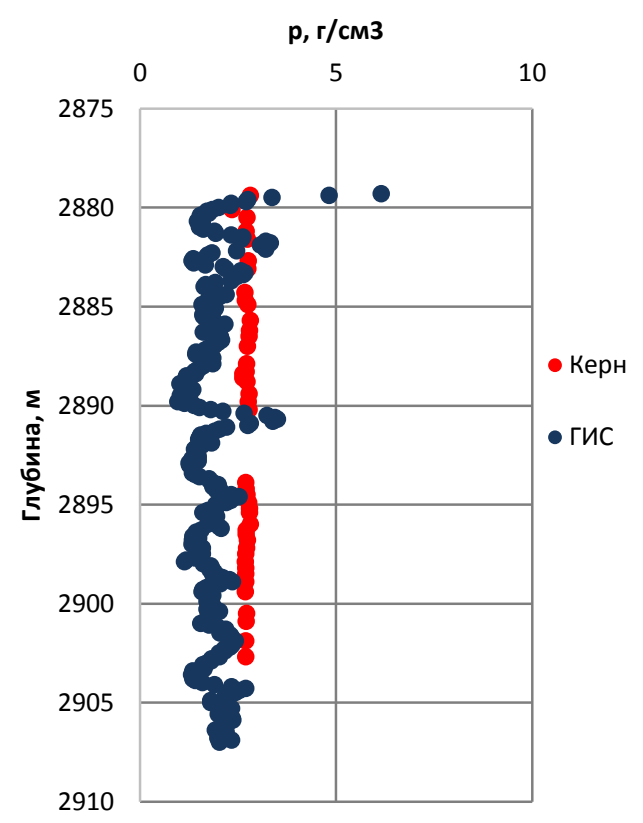

Рис. 5. Сопоставление данных плотности по керну и ГИС для варианта 2

Fig. 5. Comparison of core density and well logs data for case 2

Вариант 3. Зависимость между каротажем Альфа ПС для вертикальной эксплуатационной скважины № 2 и значениями плотности горной породы по лабораторным исследованиям керна в этой же скважине (рис. 6). 


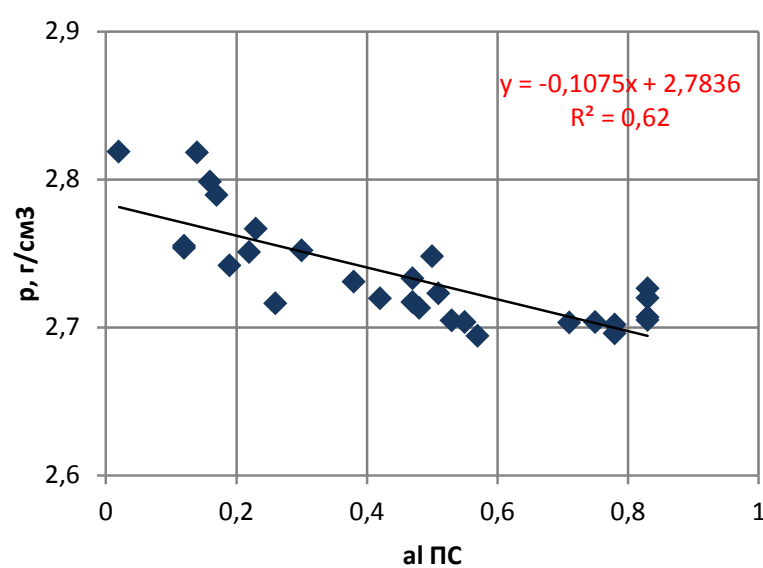

Pис. 6. Зависимость Альфа ПС (метод потенцииалов самопроизвольной поляризачии) относительно плотности горной породы по керну

Fig. 6. Dependence of Alpha SP (spontaneous potential logging) versus core density of rock

В варианте 3 была отмечена также хорошая корреляционная связь между значениями и корректное сопоставление данных ГИС-керн, что позволяет использовать данный расчет для дальнейшего прогнозирования плотности горных пород (рис. 7).

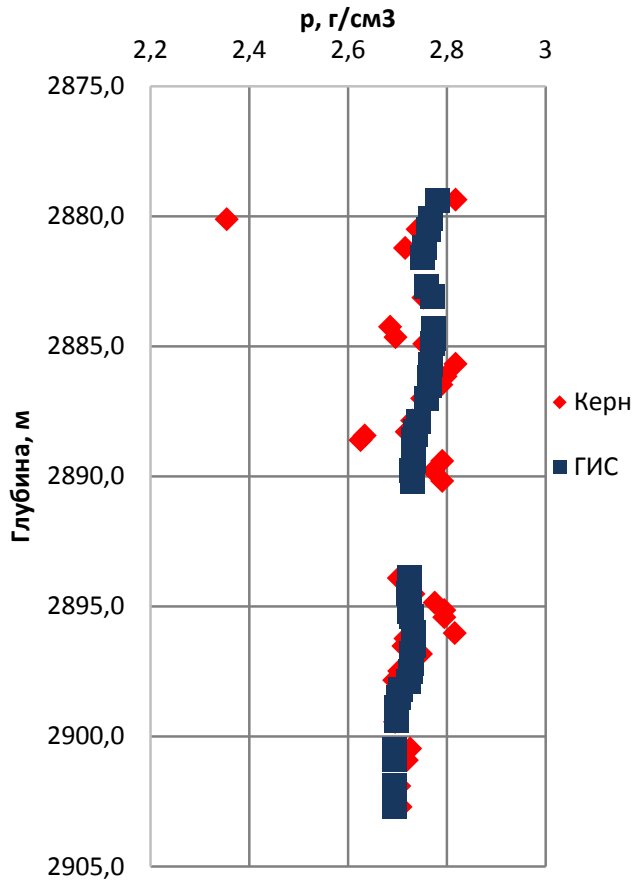

Pис. 7. Сопоставление данных плотности по керну и ГИС для варианта 3

Fig. 7. Comparison of core density and well logs data for case 3

Для каждого варианта расчета был получен диапазон значений плотности горных пород и среднее значение для всего интервала, которые представлены в табл. 3. Согласно опубликованным данным [17], где диапазон плотности для пород - известняков - составляет $2,37-2,77$ г $/ \mathrm{cm}^{3}$, а для доломитов $-2,84-2,86$ г $/ \mathrm{cm}^{3}$, необходимо отметить, что среднее значение и диапазон минимального и максимального значений не достоверно отображают значения плотности горной породы после расчетов.

Вариант 4. Зависимость между акустическим каротажем в вертикальной эксплуатационной скважине № 2 и значениями плотности горных пород из лабораторных исследований эксплуатационной скважины № 2 (рис. 8 ).

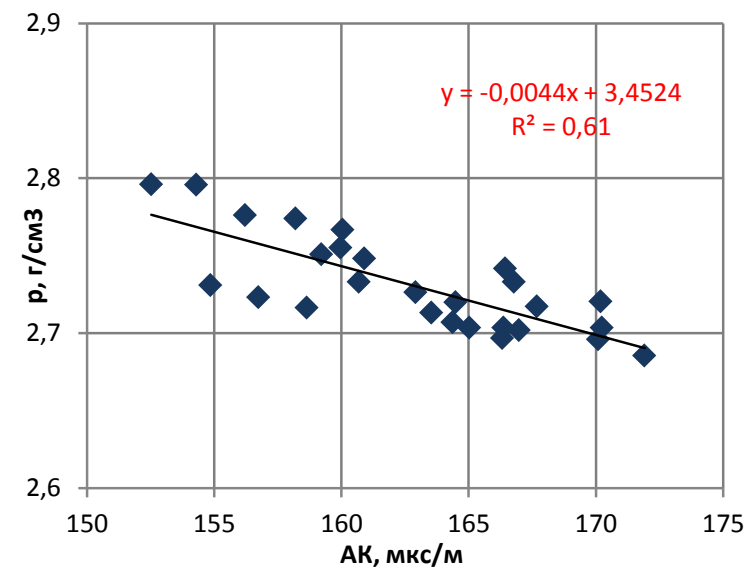

Pис. 8. Зависимость акустического каротажа относительно плотности горной породы по керну

Fig. 8. Dependence of acoustic logging versus core density

Анализируя вариант 4, можно утверждать, что данные, полученные с помощью этого варианта, характеризуют результаты, наиболее приближенные к опубликованным статистическим результатам [17], а также представляют хорошее сопоставление ГИСкерн. Результаты представлены на рис. 9.

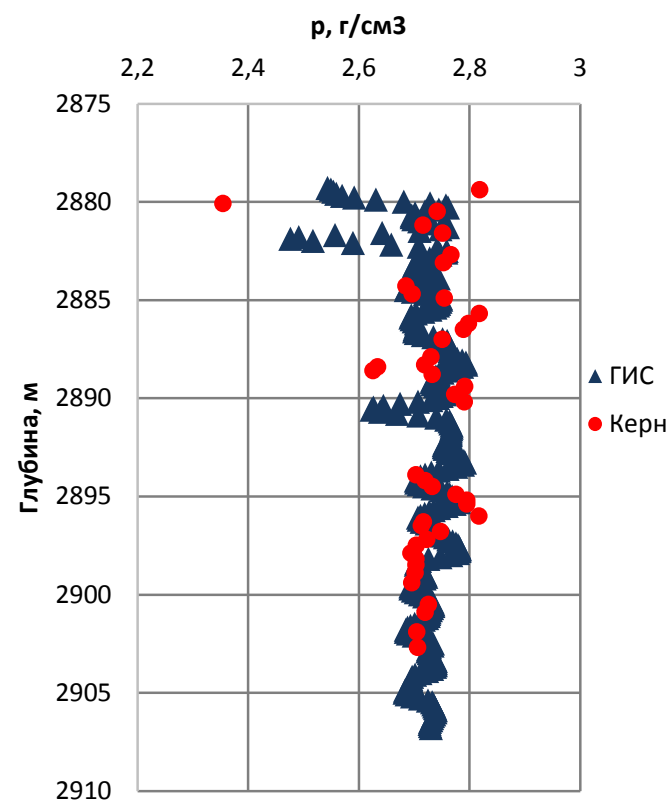

Pис. 9. Сопоставление данных плотности по керну $и$ ГИС для варианта 4

Fig. 9. Comparison of core density and well logs data for case 4 
Использование данной зависимости позволяет минимизировать неточность расчетных значений, а также данный вариант сохраняет физический смысл зависимости. Таким образом, эта корреляционная связь в дальнейшем будет использована для расчета плотности горных пород в скважинах № 2, 2R, 10, 1, 1R и 3R.

Таблица 3. Значения плотности горной породы по результатам ГИС

Table 3. Values rock density according to the results of well logs

\begin{tabular}{|c|c|c|}
\hline \multirow{2}{*}{$\begin{array}{c}\text { Вариант } \\
\text { Variant }\end{array}$} & $\begin{array}{c}\text { Диапазон } \\
\text { 3начений } \\
\text { Range of values }\end{array}$ & $\begin{array}{c}\text { Среднее значение } \\
\text { плотности } \\
\text { Average density }\end{array}$ \\
\cline { 2 - 3 } & \multicolumn{2}{|c|}{$\Gamma / \mathrm{cm}^{3}\left(\mathrm{~g} / \mathrm{cm}^{3}\right)$} \\
\hline 1 & $2,46-2,76$ & 2,70 \\
\hline 2 & $2,56-2,77$ & 2,66 \\
\hline 3 & $2,71-2,75$ & 2,73 \\
\hline 4 & $2,64-2,88$ & 2,74 \\
\hline
\end{tabular}

Для сопоставления скважинной информации с сейсмическими данными было предложено получить расчетным способом акустический импеданс, на основе материалов ГИС, используя формулу (1) для тех скважин, где имеется набор значений акустического и плотностного каротажей $[18,19]$. Результат представлен в виде гистограммы частоты встречаемости сейсмического параметра по ГИС (рис. 10).

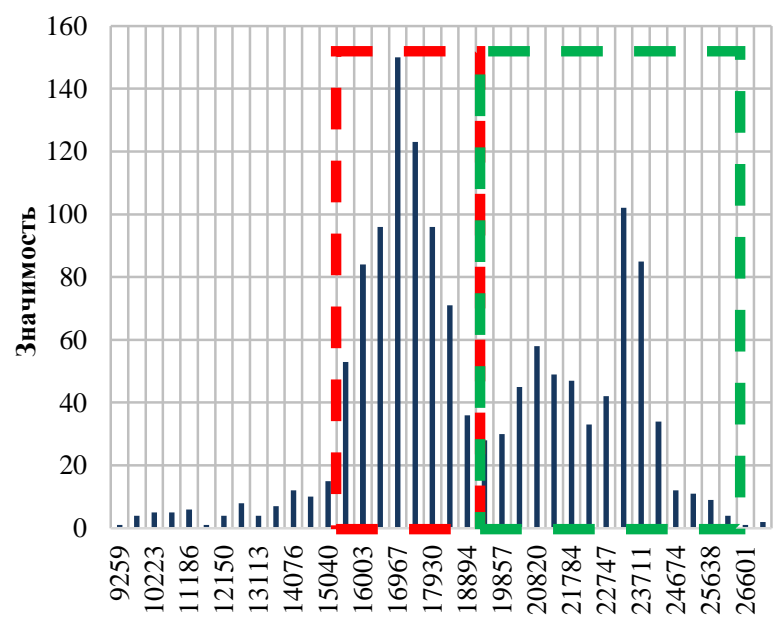

Акустический импеданс

Puc. 10. Гистограмма частоты распределения акустического импеданса по ГИС для скважин № $2,2 R$, $10,1,1 R$ и $3 R$ (области различаюшихся значений выделены красным и зелёным иветом)

Fig. 10. Histogram of the acoustic impedance distribution frequency by the well logs for wells no. 2, 2R, 10, 1 , $1 R$ and $3 R$ (blocks of different values colored with red and green)

Анализируя распределение на рис. 10, можно выделить две отчетливо выраженные области различающихся значений акустического импеданса, что, ве- роятно, будет совпадать с распределением литологии по интерпретации геофизических исследований. Для выделения и подтверждения преобладающих фаций в скважинах значения акустического импеданса были разделены на два кластера согласно табл. 2. Результат разделения на фации представлен на рис. 11.

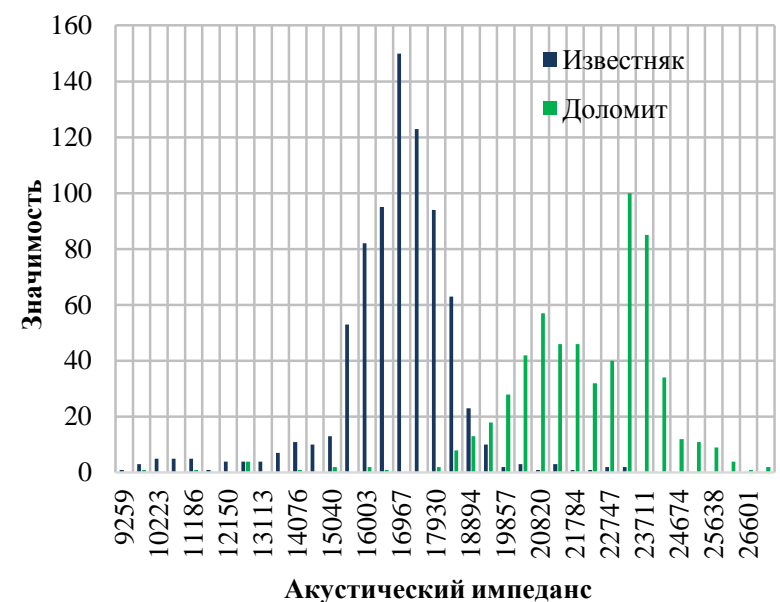

Puc. 11. Гистограмма частоты распределения акустического импеданса по ГИС для скважин № 2, 2R, $10,1,1 R$ u $3 R$

Fig. 11. Histogram of the acoustic impedance distribution frequency by the well logs for wells no. 2, 2R, 10, 1, $1 R$ and $3 R$

Из расчетных значений акустического импеданса отчетливо выделяются две области литотипов пород известняки и доломиты, что подтверждает интерпретацию разреза и выделение фаций согласно табл. 2 в скважинах № 2, 2R, 10, 1, 1R и 3R [20, 21].

\section{Заключение}

Используемые в работе методы интерпретации сложнопостроенных карбонатных толщ основаны на статистической оценке фаций с помощью данных ГИС. Необходимо отметить, что описанные способы восстановления измерений геофизических исследований позволяют приблизиться к корректной точности физических значений горной породы. Созданный на их основе подход сопоставления точечных данных с сейсмическими параметрами позволяет на количественном уровне прогнозировать распределение фаций, что в дальнейшем благоприятно сопутствует оценке перспектив сложнопостроенных коллекторов.

Ранее было отмечено несоответствие сейсмических и скважинных данных, что является возможным на данной площади исследования в связи со сложным геологическим строением территории. Дальнейшие исследования в данном направлении необходимы для более достоверного комплексирования данных, уточнения распределения фаций, что, собственно, влияет на уменьшение неопределенностей в заложении эксплуатационного фонда. 


\section{СПИСОК ЛИТЕРАТУРЫ}

1. Ежова А.В. Изучение палеозойских коллекторов СевероОстанинского нефтяного месторождения по керну и шламу. Кн. 1. - Томск: Изд-во Томского политехнического университета, 2011. - 102 c.

2. Ежова А.В., Меркулов В.П., Чеканцев В.А. Геологическая модель строения палеозойского фундамента СевероОстанинского нефтяного месторождения (Томская область) // Горный журнал. - 2012. -№ 4. - С. 35-38.

3. Изучение коллекторов нефти и газа месторождений Западной Сибири геофизическими методами / Е.И. Леонтьев, Л.М. Дорогиницкая, Г.С. Кузнецов, А.Я. Малыхин. - М.: Недра 1974. $-240 \mathrm{c}$.

4. Волкова А.А. Выбор оптимальных параметров сейсмического фациального анализа при изучении палеозойских отложений Западной Сибири // Проблемы геологии и освоения недр: Труды XXII Международного научного симпозиума им. академика М.А. Усова студентов и молодых ученых. - Томск: Томский политехнический университет, 2018. - Т. І. - С. 383-384.

5. Волкова А.А., Меркулов В.П. Информативность 3D сейсморазведки при оценке перспектив нефтегазоносности отложений Палеозойского фундамента Западной Сибири // СанктПетербург 2018: 8-ая международная геолого-геофизическая конференция и выставка EAGE. Тезисы доклада. - СПб., 2018. URL: earthdoc.eage.org/publication/publicationdetails/?publication= 91397 (дата обращения 18.04.2020).

6. Chopra S., Marfurt K. Seismic attributes for prospect identification and reservoir characterization // Geophysical developments. - Tulsa: SEG, 2007. - 464 p

7. Seismic facies analysis and structural interpretation of the Sandakan sub-basin / K. Futalan, A. Mitchell, K. Amos, G. Backe // AAPG international conference and exhibition. - Singapore, 2012. - P. 1-18. URL: http://www.searchanddiscovery.com/pdfz/ documents/2012/30254futalan/ndxfutalan.pdf.html (дата обращения 10.05.2020).

8. White R.E. Properties of instantaneous seismic attributes: The Leading Edge. - 1991. - № 10 (7). - P. 26-32.

9. Djebbar T., Erle C.D. Petrophysics - theory and practice of measuring reservoir rock and fluid transport properties // Elsevier. 2004. -926 p.
10. Pirson S.J. Sedimentological studies by log curve shapes. Geologic well $\log$ analysis // Gulf publishing company. -1983 - P. 36-58

11. Дахнов В.Н. Интерпретация результатов геофизических исследований скважин. - М.: Недра, 1982. - 448 с.

12. Сейсмофациальный анализ и возможности прогнозирования литотипов пород по данным сейсморазведки / Г.Д. Ухлова, В.В. Соломатин, Л.И. Штифанова, Т.И. Чернышова // VII Bceроссийское литологическое совещание. - Новосибирск, 2013. - C. 227-230.

13. Прогнозирование структуры и свойств природных резервуаров на основе комплексной интерпретации сейсмических и скважинных геолого-геофизических данных / А.П. Жуков, В.А. Жемчугова, К.А. Эпов, С.Л. Федотов // Технологии сейсморазведки. - 2006. - № 1. - С. 69-78.

14. Sheriff R.E. Reservoir geophysics. - Tulsa: SEG, 1992. - 401 p.

15. Дементьев Л.Ф. Статистические методы обработки и анализа промыслово-геологических данных. - М.: Недра, 1966. $206 \mathrm{c}$.

16. A genetic approach to the prediction of petrophysical properties / F.X. Jian, C.Y. Chork, I.J. Taggart, D.M. McKay, R.M. Bartlett // Journal of Petroleum Geology. - 1994. - V. 17. - P. 71-88.

17. Бондарев В.И., Крылатков С.М. Анализ данных сейсморазведки. - Екатеринбург: Изд-во УГГГА, 2002. - 212 с.

18. Seismic facies analysis based on $3 \mathrm{D}$ multiattribute volume classification, La Palma Field, Maracaibo, Venezuela / V. Linari, M. Santiago, C. Pastore, K. Azbel, M. Poupon // The Leading Edge. 2003. - P. 32-36.

19. Дюбрюль О. Геостатистика в нефтяной геологии. - М.; Ижевск: Институт компьютерных исследований, НИЦ «Регулярная и хаотическая динамика», 2009. - 256 с.

20. Чучалина К.Ю. Статистическое обоснование сейсмофацильного анализа сложнопостроенных карбонатных коллекторов Северо-Останинского нефтяного месторождения: магистерская диссертация. - Томск, 2019. - 84 с

21. Volkova A., Chuchalina K., Merkulov V. Statistical justification of seismic facies analysis of complex carbonate reservoir // European Association of Geoscientists \& Engineers. - Saint Petersburg, 2020. - P. 1-5. URL: https://doi.org/10.3997/22144609.202053102 (дата обращения: 15.05.2020).

Поступила 12.04.2021 2.

\section{Информация об авторах}

Чучалина К.Ю., магистрант отделения геологии Инженерной школы природных ресурсов Национального исследовательского Томского политехнического университета.

Коровин M.O., кандидат геолого-минералогических наук, доцент отделения нефтегазового дела Инженерной школы природных ресурсов Национального исследовательского Томского политехнического университета. 
UDC 550.832

\title{
APPLICATION OF SEISMIC FACIES ANALYSIS FOR EVALUATING THE PROSPECTS OF COMPLEX CARBONATE RESERVOIR ON THE EXAMPLE OF OIL DEPOSIT (BY THE DATA OF WELL LOGS)
}

\author{
Kristina Yu. Chuchalina', \\ K.Yu.Chuchalina@gmail.com \\ Mikhail O. Korovin1, \\ korovinmo@hw.tpu.ru \\ 1 National Research Tomsk Polytechnic University, \\ 30, Lenin avenue, Tomsk, 634050, Russia.
}

\begin{abstract}
The relevance of the research is determined by the need to minimize the uncertainties of geological interpretation using various classification algorithms in processing the entire complex of geological and geophysical data.

The main aim of the research is the forecast and statistical justification of the distribution of facies based on geophysical information on the example of one of the deposits in Tomsk region.

The object of the study is the Paleozoic sediments of the southeastern part of the West Siberian Plate - reservoirs of complex carbonate strata where terrigenous formations and carbonate varieties - limestone and dolomite - are encountered. Based on the conditions for constructing a seismic facies map, a study window was selected. It covers a rock volume of $40 \mathrm{~m}$.

Research methods are based on the application of classification algorithms to a seismic signal, which divide the object under study into regions that are homogeneous by a number of signs. In the classification algorithm along the seismic track geophysical studies of wells and laboratory studies of the core, which involves the integration of information, are very often included. A comprehensive interpretation of seismic and borehole data allows predicting at a qualitative level lithofacial variability in local areas, which contributes to a more rational placement of production wells.
\end{abstract}

The lithotypes of productive strata rocks were identified and ranked based on comparison of the seismic parameter - acoustic impedance, according to borehole and seismic information. Data comparison was carried out using reconstructed density logging measurements.

\section{Key words:}

Seismic facies analysis, seismic facies map, facies, well logging, acoustic impedance, Paleozoic deposits.

\section{REFERENCES}

1. Ezhova A.V. Izuchenie paleozoyskikh kollektorov SeveroOstaninskogo neftyanogo mestorozhdeniya po kernu i shlamu [The study of Paleozoic reservoirs of the North Ostaninsk oil field by core and sludge]. Tomsk, TPU Publ. house, 2011. B. 1, 102 p.

2. Ezhova A.V., Merkulov V.P., Chekantsev V.A. Geologicheskaya model stroeniya paleozoyskogo fubdamenta Severo-Ostaninskogo neftyanovogo mestorozhdenya (Tomskaya oblast) [Paleozoic basement geological structure model of Northern Ostaninsk oil field (Tomsk region)]. Mountain Journal, 2012, no. 4, pp. 35-38.

3. Leontyev E.I., Doroginitskaya L.M., Kuznetsov G.S., Malykhin A.Ya. Izuchenie kollektorov nefti i gaza mestorozhdeniy Zapadnoy Sibiri geofizicheskimi metodami [Study of oil and gas reservoirs in Western Siberia by geophysical methods]. Moscow, Nedra Publ., 1974. $240 \mathrm{p}$.

4. Volkova A.A. Vybor optimalnykh parametrov seysmicheskogo fatsialnogo analiza pri izuchenii paleozoiskikh otlozheniy Zapadnoy Sibiri [Selection of optimal parameters of seismic facies analysis in the study of Paleozoic deposits in Western Siberia]. Problemy geologii $i$ osvoeniya nedr. Trudy XXII Mezhdunarodnogo nauchnogo simpoziuma imeni akademika M.A. Usova studentov molodykh uchenykh [Problems of geology and subsoil development. Proc. of the XXII International Scientific Symposium named after Academician M.A. Usov for students and young scientists] Tomsk, TPU, 2018. Vol. I, pp. 383-384.

5. Volkova A.A., Merkulov V.P. Informativnost 3D seysmorazvedki pri otsenke perspektiv neftegazonosnosti otlozheny Paleozoyskogo fundamenta Zapadnoy Sibiri [Information value of 3D seismic in evaluation the prospects of oil and gas fields of the Paleozoic basement of Western Siberia]. 8 Mezhdunarodnaya geologo-fizicheskaya konferentsiya i vystavka. Sankt Peterburg-2018 [ $8^{\text {th }}$ EAGE Saint Petersburg International Conference and Exhibition. Extended abstract]. St-Petersburg, 2018. Available at: earthdoc.eage. org/publication/publicationdetails/?publication $=91397$ (accessed 18 April 2020).
6. Chopra S., Marfurt K. Seismic attributes for prospect identification and reservoir characterization. Geophysical developments. Tulsa, SEG, 2007. $464 \mathrm{p}$.

7. Futalan K., Mitchell A., Amos K., Backe G. Seismic facies analysis and structural interpretation of the San-dakan sub-basin. $A A P G$ international conference and exhibition. Singapore, 2012. Available at: www.searchanddiscovery.com/documents/2012/30254futalan/ ndx_futalan.pdf (accessed 10 May 2020).

8. White R.E. Properties of instantaneous seismic attributes. The Leading Edge, 1991, no. 10 (7), pp. 26-32.

9. Djebbar T., Erle C.D. Petrophysics - theory and practice of measuring reservoir rock and fluid transport properties. Elsevier, 2004, $926 \mathrm{p}$.

10. Pirson, S.J. Sedimentological studies by log curve shapes. Geologic well log analysis, 1983, pp. 36-58.

11. Dakhnov V.N. Interpetatsiya resultatov geofizicheskikh issledovaniy skvazhin [Interpretation of the results of geophysical surveys of wells]. Moscow, Nedra Publ., 1982. 448 p.

12. Ukhlova G.D., Solomatin V.V., Shtifanova L.I., Chernyshova T.I. Seismofatsialniy analiz i vozmozhnosti prognozirovaniy litotipov porod po dannym siysmorazvedki [Seismic facies analysis and forecasting features of lithotypes of rocks according to seismic data]. VII Vserossiyskay Litologicheskay Konferentsiya [VII AllRussian Lithological Conference]. Novosibirsk, 2013. pp. 227-230

13. Zhukov A.P., Zhemchugova V.A., Epov K.A., Fedotov S.L. Prognozirovanie structury i svoystv prirodnykh rezervuarov na osnove kompleksnoy interpretatsii seismicheskikh i skvazhinnykh geologo-geofizicheskikh dannykh [Prediction of the structure and properties of natural reservoirs based on a comprehensive interpretation of seismic and borehole geological and geophysical data]. Seismic exploration technologies, 2006, no. 1, pp. 69-78.

14. Sheriff R.E. Reservoir geophysics. Tulsa OK, SEG, 1992. 401 p.

15. Dementiev L.F. Statisticheskie metody obrabotki i analiza promyslovo-geologicheskikh dannykh [Statistical methods for processing and analyzing field geological data]. Moscow, Nedra Publ., 1966. $206 \mathrm{p}$. 
16. Jian F.X., Chork C.Y., Taggart I.J., McKay D.M., Bartlett R.M. A genetic approach to the prediction of petrophysical properties. Journal of Petroleum Geology, 1994, vol. 17, pp. 71-88.

17. Bondarev V.I., Krylatkov S.M. Analiz dannykh seismorazvedki [Analysis of seismic data]. Yekaterinburg, UGGAA Publ. House, 2002. $212 \mathrm{p}$.

18. Linari V., Santiago M., Pastore C., Azbel K., Poupon M. Seismic facies analysis based on 3D multiattribute volume classification, La Palma Field, Maracaibo, Venezuela. The Leading Edge, 2003, pp. 32-36.

19. Dubryul O. Geostatistika v neftaynoy geologii [Geostatistics in petroleum geology]. Moscow, Izhevsk, Institute for Computer Research, SRC «Regular and chaotic dynamics», 2009. 256 p.
20. Chuchalina K.Yu. Statisticheskoe obosnovanie seismofatsialnogo analiza slozhnopostroennykh karbonatnykh kollektorov SeveroOstaninskogo neftynogo mestorozhdeniya. Magisterskay Diss. [Statistical justification of seismic facies analysis of complex carbonate reservoirs of the North Ostaninskoye oil field. Master's thesis]. Tomsk, 2019. $84 \mathrm{p}$.

21. Volkova A., Chuchalina K., Merkulov V. Statistical justification of seismic facies analysis of complex carbonate reservoir. St- Petersburg, European Association of Geoscientists \& Engineers, 2020. Available at: https://doi.org/10.3997/2214-4609.202053102 (accessed 15 May 2020).

Received: 12 April 2021.

\section{Information about the authors}

Kristina Yu. Chuchalina, master student, National Research Tomsk Polytechnic University.

Mikhail O. Korovin, Cand. Sc., associate professor, National Research Tomsk Polytechnic University. 